\title{
1A LIDERANÇA SEGUNDO A EXEPERIÊNCIA DE VIDA DO PROFESSOR CASTRO
}

\author{
Artur Santa Catarina M. Eng. \\ Programa de Pós-graduação em Engenharia de Produção
}

\section{INTRODUÇÃO}

Através desta pesquisa mostro o que compreendi sobre a experiência de ser líder do professor João Ernesto Escosteguy Castro. Faço tal pesquisa através de uma abordagem da fenomenologia hermenêutica (Van Mannen,1990), buscando o significado da liderança para o professor. A pesquisa foi feita utilizando a técnica da entrevista aprofundada em três etapas (Seidman, 1998). $\mathrm{O}$ artigo mostra a transcrição de alguns trechos da entrevistas além de uma série de considerações sobre a experiência de vida do Professor Castro, como líder, com base em suas próprias reflexões. O artigo mostra o histórico da liderança para o Professor, destaca alguns temas que surgiram como importantes no decorrer das entrevistas e, por fim, reflexões sobre tais temas, buscando a essência do que era a liderança para o Professor Castro. As entrevistas e o texto foram realizados no final do ano de 2004.

\section{EXPERIÊNCIA VIVIDA}

\section{Histórico}

O professor Castro teve uma formação muito forte dos Jesuítas Alemães, em Porto Alegre, onde os próprios padres lecionavam. Teve experiências como líder logo jovem, sendo Diretor do grêmio estudantil tanto no Ginásio quanto no

\footnotetext{
${ }^{1}$ Escrito em novembro de 2004 e não publicado.
} 
Científico. Nestas ocupações, dentre os grandes motivadores estaria a inatividade dos grupos, que precisavam de uma liderança para não "morrerem".

É graduado como Engenheiro Metalúrgico pela Universidade Federal do Rio Grande do Sul, curso caracterizado na época, por bons professores, com forte atuação profissional, porém, sem tanta visão da universidade como sendo um centro de pesquisa. A busca por formar uma universidade no mesmo estilo das research universities dos Estados Unidos, que eram centros de pesquisa, que o Professor Castro começou a participar de atividades de liderança na UFSC.

O professor Castro cita dois casos muito interessantes de liderança da UFSC. Um deles foi o Raul Valentin da Silva, um dos que criou a Engenharia de Produção em SC, praticamente no Sul do Brasil e outro, o Longuinho da Costa Machado Leal, primeiro Diretor eleito em um processo de democratização do centro tecnológico. O Raul foi um líder que teve a visão da Engenharia de Produção, achou importante o desenvolvimento desta formação acadêmica e realizou o trabalho de criar as estruturas necessárias para a viabilização desta carreira. A Engenharia Industrial que antes estava ligada ao Departamento de Engenharia de Mecânica, desmembrou-se, dando origem ao Departamento de Engenharia de Produção, ao Programa de Pós-graduação em Engenharia de Produção, à Graduação em Engenharia de Produção. Era uma pessoa bem preparada que teve a visão e o ânimo de enfrentar a forte resistência da do Departamento de Engenharia Mecânica. O Longuinho da Costa teve também um papel importante nestes desenvolvimentos, liderando um processo de democratização do centro tecnológico, conseguindo conciliar a manutenção de algumas estruturas de poder com o surgimento de novos cursos e departamentos, trabalhando com transparência em pontos como orçamento e distribuição de informações, que antes era complicado, segundo o Professor Castro.

Passando por anos bastante difíceis, de 1979 à 1981, com problemas de meios e salários, a Engenharia de Produção contou com a participação do professor Castro que trabalhou junto com outros professores no processo de firmamento do curso de graduação em Engenharia de Produção. 
O que ele percebeu quando chegou na UFSC em 1977 pode ser melhor compreendido a partir de suas palavras:

"Quando eu cheguei aqui em 77, 78, eu entrei professor 78, eu achei que tinha um departamento consolidado, e quando eu vejo, 79, 80, uma crise enorme na UFSC e no departamento também."

"uma mudança enorme no departamento, os que puxavam o processo até 80 vão quase todos embora, nos estávamos como responsáveis por aquele curso novo, um bom número de jovens, e o departamento meio perdido, a nota da pósgraduação caindo."

Foi uma mudança grande, projetos pessoais e alguns prazeres foram adiados ou deixados de lado como ele mesmo cita: “...ia mais ao cinema, não perdia conserto, pescava e viajava mais...”. O leitor grave isto pois no final do artigo estas suas origens serão resgatadas.

Ficou envolvido com a chefia do departamento até 1984, trabalhando para criar estruturas de laboratórios, trazer professores doutores e outras estruturas necessárias para o desenvolvimento do curso. Apesar de ter assumido tal posto, nunca o procurou, viu-se obrigado pela situação a participar destes processos para tirar o curso destas situações difíceis.

Saindo da chefia, o professor Castro, junto com os professores Casarotto e Ernani montaram um laboratório que teria a função de aumentar o contato dos alunos de graduação em Engenharia de Produção com o departamento. Montaram, então, o Laboratório de Sistemas de Apoio à Decisão, coordenado pelo professor Castro até seus últimos dias.

Além da participação universitária, o professor Castro se via bastante influenciado pelo Rotary, grupo que possui uma liderança baseada em voluntariado e princípios, segundo o professor, derivados da cultura anglosaxônica, e da religião protestante. O estilo do líder seria de análogo ao capitão ou o Team Leader, algo oposto ao que seria um líder que se considerasse o dono time, que segundo o professor, seria derivado da cultura ibero-lusitana e da Igreja Católica. 
Ainda, além do Rotary e da Universidade o professor destaca sua participação como Comodoro Diretor de Finanças do late Clube Santa Catarina - Veleiros da Ilha.

\section{Principais Temas}

No item anterior, eu tentei passar um pouco do histórico da liderança para o professor Castro. Este trabalho, porém, objetiva chegar a um nível um pouco mais profundo de entendimento sobre a experiência de liderança. Visualizando o histórico acima, pode-se perceber que há uma série de aspectos que fazem parte do que é liderar para o professor. Estes aspectos aqui são chamados de "temas" e a seguir, cada um dos temas identificados como essenciais para o entendimento da liderança para o Professor Castro.

Para compreender um pouco mais o significado destes temas, temos que imaginar que, a consideração destes diferentes temas e a influência que um exerce sobre o outro, nos permite estruturar o que significava a liderança para o professor Castro.

\section{Surgimento da liderança/evitar colapso}

A liderança para o professor Castro, tanto em suas experiências como líder quanto como liderado reforçam a importância das situações para o surgimento de lideranças. Tais situações podem ser vistas tanto como adversidades do meio como por oportunidades que surgem e necessitam que alguém tenha a visão de percebê-as aproveitá-las.

Segundo o Castro, a liderança traz consigo diversos afazeres, responsabilidades e disputas pelo poder, porém, no seu caso, a intenção inicial era estar longe, tanto das disputas de poder quanto das responsabilidadesextra que cabem ao líder. Situações que poderiam levar as organizações ao colapso muitas vezes fizeram que ele assumisse a liderança, apesar de não busca-la e declarar explicitamente ter aversão ao poder. Isto pode ser reforçado com as suas palavras: "responsabilidade é onerosa, porém, alguém 
tem que fazer", isto é, era situações que exigiam liderança e que ele não poderia fugir a estas responsabilidades e deixar "o barco afundar".

Um dos exemplos narrados que representaria uma liderança de sucesso foi o caso do Professor Raul Valentin da Silva. Este exemplo reforça o surgimento de alguns líderes devido às oportunidades. No caso narrado pelo professor Castro, o Raul teve a visão da importância da formação de Engenheiro de Produção devido às suas experiências profissionais e, em um momento de abertura do centro tecnológico, liderou o processo de criação do Departamento de Engenharia de Produção na UFSC. Para este caso, vale a metáfora utilizada por Castro: "passou o cavalo encilhado e ele montou".

$\mathrm{O}$ professor também citou ter visto casos em que as pessoas procuram o poder e a liderança, muitas vezes, sem uma causa que não seja a própria obtenção de poder.

\section{Atribuições do líder}

Para o professor Castro, a liderança teria como principais atribuições, fazer a articulação interna e externa do grupo e ainda evitar conflitos que destruam o grupo. Para referir-se a esta última atribuição ele usa algumas expressões como "evitar o circo pegar fogo", "evitar que todo mundo brigue e acabe não saindo nada". Isto é, o líder tem esta função de conciliar interesses e acalmar ânimos.

$\mathrm{Na}$ articulação interna a idéia é de "fazer o pessoal tocar o barco", delegando e cobrando tarefas de acordo com o talento de cada um para atingir os objetivos do grupo. Ele reforça a cobrança dos resultados dizendo que: "delegar tem que cuidar para não confundir com abandonar, tem que verificar se a tarefa foi feita, tem que marcar gol durante o tempo do jogo". Ainda, o líder tem a função de, seguindo a metáfora anterior, trocar alguns "jogadores", caso eles não estejam correspondendo. Antes de "trocar o jogador", a função de motivar determinados integrantes da equipe também está presente entre as atribuições de articulador interno. Ele brinca dizendo: "vamos lá, te anima, Deus não te detesta", buscando animar alguns integrantes desanimados do grupo. 
Como articulador externo, suas principais atribuições seriam de observar oportunidades de negócio, utilizando um pouco de intuição para "ver de que lado o vento está soprando", porém, ele focaria suas atenções na busca de informações. Ele fala:

"Muita busca de informação, uma teia de relações grandes, uma busca de informações enormes na área, a inteligência competitiva, tem que ter listas no setor, né que a gente recebe, dados das oportunidades do setor, conversar com outras pessoas que poderiam estar necessitando de trabalho, de idéias, não dá para ficar parado, tem que ir um pouco atrás, ficar parado as oportunidades não chegam".

Deixando muito claro neste trecho da entrevista o papel de buscar informações fundamentais para o desenvolvimento da organização.

\section{Estilo de liderança}

O estilo de liderança do Professor Castro talvez possa ser mais bem entendido a partir do estilo de liderança pregado por uma instituição que o professor considera como uma "grande escola", o Rotary. Segundo o professor, os estudos sobre liderança vêem dos princípios do século passado, vindo da tradição americana, onde se fala em team leader, isto é, o líder do time. Tal filosofia advinda de uma grande tradição do Rotary, provavelmente tendo iniciado com grandes empresas organizadas. A maneira de manter a coesão do grupo seria semelhante a da igreja, com a definição de programas mensais, com muita organização, definindo diariamente os projetos. No Rotary o trabalho é voluntário, fazendo com que os participantes tenham uma motivação própria para estarem ali, e como ele fala, "o pessoal tem que ter o perfil". Mesmo assim, para manter a motivação, são realizadas reuniões semanais, e todo o mês uma reunião com caráter mais festivo. O presidente do Rotary também dispõe de uma literatura muito forte de apoio, e este, tende a realizar visitas.

Dentre alguns princípios desta liderança Rotariana, um seria considerar todos como sendo iguais, onde o presidente é geralmente eleito por todos. As 
tomadas de decisão não são essencialmente democráticas, porém, Castro afirma que a maneira como é estruturada a sucessão garante que as principais linhas sejam ouvidas.

Em oposição a este estilo, o professor citou um estilo mais encontrado em culturas ibéricas e portuguesas na América Latina, onde o líder se considera praticamente, o "dono do time", ou "el dueño de hacienda". Em tal estilo, a maneira motivar seria a remuneração ou então, o medo do "chicote", deixando o grupo muitas vezes dependente da existência do pagamento, como ele cita "acabou o dinheiro, todo mundo vai embora ressentido".

O professor considerava a existência dois estilos de liderança baseados em motivação, que seria o voluntariado, citando os exércitos de Napoleão, que eram formados pelo povo que lutaria pelo seu país, "les cituaians". Segundo ele, este sistema teria funcionado muito bem contra os exércitos de mercenários existentes na Europa naquela época. O outro estilo que funcionaria por motivação seria o sistema de pagamento. Além desses, o professor cita o sistema do "inferno", do "chicote", que segundo ele, seria muito o sistema da Igreja Católica, do fogo do inferno, do pecado original. Segundo ele, "pode funcionar, mas não por muito tempo".

Um dos pontos-chave no estilo de liderança do professor é o comprometimento. Isto pode ser percebido em alguns momentos em que pedi que ele fizesse um paralelo entre a liderança dentro de sua família e a liderança profissional. O principal diferencial seria a busca de um comprometimento para a vida, no caso da família enquanto em grupos profissionais, o comprometimento muitas vezes depende de pagamentos e se restringe ao tempo de duração dos recursos ou dos projetos. Explorando o assunto ele mencionou várias pessoas que tiveram orientação acadêmica que mantém contato até hoje, que ainda fazem parte do time. Seria talvez, um meio termo entre a liderança na família e a liderança profissional. Uma das características do seu estilo, seria a busca de um comprometimento mais longínquo.

Dificuldades 
A liderança é considerada como um processo oneroso, porém, necessário. Dentre as dificuldades citadas, a de ter que acordar 4:30 $\mathrm{h}$ da madrugada, perder noites de sono, ter problemas de saúde, ter que lidar com disputas de poder sem querer o poder, ter menos tempo para a família.

Porém, a liderança não é algo que fecha com os planos pessoais do professor e, em algumas vezes vai de encontro. Segundo o professor, partes dos seus planos pessoais acabaram sendo adiados ou deixados de lado devido à necessidade de focar esforços em liderar e vencer as dificuldades organizacionais que o impulsionaram à liderança, como pode ser percebido em uma citação "...uma coisa puxou a outra, ai realmente sacrifiquei meus projetos pessoais... ". Como já vimos, muitas vezes, o que trouxe o professor Castro à liderança foram situações - oportunidades ou crises - nas quais a organização (universidade na maior parte das experiências citadas). Porém, em tais situações, estava implícita uma visão maior, de fazer evoluir a universidade brasileira e a engenharia de produção. Ver o descaso do governo brasileiro (em diversos mandatos presidenciais) para com um modelo de universidade baseado em ensino, pesquisa e extensão é, sem dúvida, sua maior dificuldade. Utilizando suas próprias palavras: "o que desanima é ver no Brasil, nossas elites, não conseguirem aproveitar todo esse potencial [muitos jovens dispostos e bem preparados]".

\section{Motivação e Retorno}

Se a maior dificuldade, como foi posto acima, era não ver a concretização da sua visão, a maior motivação era vencer estas dificuldades para trazer evolução à universidade brasileira. Em sua visão, a universidade deveria ser profissional, com apoio do governo, propiciando ensino, pesquisa e extensão estruturados e aproveitando o capital intelectual, capital este que o Brasil tem de sobra. 


\section{CONSIDERAÇÕES FINAIS}

No decorrer do trabalho foi possível perceber que os temas não estão isolados, havendo uma relação entre eles. Esta inter-relação nos aproxima mais da estrutura do significado do que é ser líder para o Professor Castro.

As situações e a sua formação definiram o seu surgimento como líder. Botava-se a disposição da organização uma vez que esta precisasse. Foram situações que segundo ele, não tinha como não assumir o comando, não sendo o caso, de que a liderança era por ele almejada ou um plano pessoal. Uma vez estando encarregado da liderança, haveria algumas atribuições inerentes ao líder como: a articulação interna e externa do grupo; evitar conflitos; motivar os integrantes, buscando um comprometimento em prol de valores maiores; delegar e cobrar tarefas; substituir participantes caso necessário; buscar informações; construir uma teia de relacionamentos e gerar oportunidades . O Professor Castro tinha seu estilo de liderar, daí surge o seu estilo de liderança, suas formas de conduzir e manter motivado o grupo. Ele buscava motivar os liderados em torno de uma visão maior, de aprendizado e de construção de uma universidade maior e melhor. Ele se via como sendo o "capitão" e não o "dono" do time, isto Ihe permitia delegar tarefas, compartilhar os resultados, formando uma estrutura mais longínqua.

O professor castro era motivado por esta visão de construir uma universidade profissional, realizando ensino, pesquisa e extensão, deixando um pouco objetivos financeiros em prol de um ganho mais nobre para ele e para os seus colaboradores. O maior desânimo era perceber as dificuldades institucionais do Brasil, o poder público, em fazer a parte que the cabe, que é dar as condições, isto é, os meios para que os pesquisadores, professores e novos talentos se desenvolvam junto com o país. Em prol desta visão, alguns projetos pessoais foram adiados ou perderam prioridade.

Quando perguntado de quais seriam suas visões para a sua atuação como líder, o professor respondeu: "Agora eu queria me sossegar mais, quero retornar um pouco às origens". Porém como ele mesmo fala, "do futuro somente o bom Deus sabe", e em surgindo oportunidades irrecusáveis, o que fazer? 
Para fechar o artigo, o professor Castro utiliza mais uma de suas interessantes metáforas para dizer o que é para ele ser líder:

"Levar o barco para um porto seguro, com a tripulação inteira e o barco inteiro, ter uma missão e cumprir aquela missão, e levar todo mundo junto, devolve o barco para o dono, e desembarca os passageiros em terra sem perder uma unha. Desvia das tempestades, não cai ninguém no mar. Tem que traçar rotas, tem que abastecer o barco, pagar a tripulação, alimentar os passageiros. Perceber a missão e cumpri-la. Na verdade a gente traça uma rota mas tem que mudar a tática, muda o vento, muda a maré, rasga uma vela, mas continua com a meta, de levar para aquele porto seguro. A vida acho muito parecida como uma regata, como um barco a vela, nem um barco a motor, dá para chegar lá, mas as vezes a gente não consegue ir reto, tem que ir cambando, tem que fazer a travessa, tem que ir no contra vento, mas manter a cabeça, quero chegar lá e com o barco inteiro, sem jogar o pessoal na água. Em um tempo certo, uma regata tem um tempo certo. As vezes não é bom chegar em primeiro lugar, os que forçam muito para chegar em primeiro lugar, quebram". 


\section{BIBLIOGRAFIA CONSULTADA}

Seideman, I. Interviewing as qualitative research. $2^{\text {nd }}$ ed. New York: Teachers College press, 1998. Cap 1 e 2.

Phenomenologyonline. Glossary. www.phenomenologyonline.com.br

Van Manen, M. Reseraching lived experience. New York : State of New York Press, 1990. 